\title{
Change in fracture risk and fracture pattern after bariatric surgery: nested case-control study
}

\author{
Catherine Rousseau, ${ }^{1,2}$ Sonia Jean, 2,3 Philippe Gamache, ${ }^{3}$ Stéfane Lebel, ${ }^{4}$ Fabrice Mac-Way, ${ }^{1,2}$ \\ Laurent Biertho, ${ }^{4}$ Laëtitia Michou, ${ }^{1,2}$ Claudia Gagnon ${ }^{1,2,5}$
}

${ }^{1}$ Endocrinology and Nephrology Unit, CHU de Québec Research

Centre, Quebec City, Canada, G1V 4G2

${ }^{2}$ Department of Medicine, Laval University, Quebec City, Canada, G1V 0 A6

Institut national de santé publique du Québec, Quebec City, Canada, G1V 5B3

${ }^{4}$ Quebec Heart and Lung Institute - Laval University, Quebec City, Canada, G1V 4G5 5 Institute of Nutrition and Functional Foods, Quebec City, Canada, G1V OA6

Correspondence to: C Gagnon claudia.gagnon@

crchudequebec.ulaval.ca Additional material is published online only. To view please visit the journal online.

Cite this as: $B M$ J 2016;354:13794 http://dx.doi.org/10.1136/bmj.i3794

Accepted: 27 June 2016

\section{ABSTRACT}

OBJECTIVE

To investigate whether bariatric surgery increases the risk of fracture.

\section{DESIGN}

Retrospective nested case-control study.

SETTING

Patients who underwent bariatric surgery in the province of Quebec, Canada, between 2001 and 2014, selected using healthcare administrative databases.

\section{PARTICIPANTS}

12676 patients who underwent bariatric surgery, age and sex matched with 38028 obese and 126760 non-obese controls.

\section{MAIN OUTCOME MEASURES}

Incidence and sites of fracture in patients who had undergone bariatric surgery compared with obese and non-obese controls. Fracture risk was also compared before and after surgery (index date) within each group and by type of surgery from 2006 to 2014 . Multivariate conditional Poisson regression models were adjusted for fracture history, number of comorbidities, sociomaterial deprivation, and area of residence.

RESULTS

Before surgery, patients undergoing bariatric surgery (9169 (72.3\%) women; mean age 42 (SD 11) years) were more likely to fracture $(1326 ; 10.5 \%)$ than were obese (3065; 8.1\%) or non-obese (8329; 6.6\%) controls. A mean of 4.4 years after surgery, bariatric patients were more susceptible to fracture $(514 ; 4.1 \%)$ than were obese $(1013 ; 2.7 \%)$ and non-obese $(3008 ; 2.4 \%)$ controls. Postoperative adjusted fracture risk was higher in the bariatric group than in the obese (relative risk $1.38,95 \%$ confidence interval 1.23 to 1.55 ) and nonobese $(1.44,1.29$ to 1.59$)$ groups. Before surgery, the risk

\section{WHAT IS ALREADY KNOWN ON THIS TOPIC}

Bariatric surgery leads to an increase in bone turnover markers and a decrease in bone mineral density

Whether these abnormalities in bone metabolism translate into an increase in fracture risk remains uncertain, as the three studies assessing the effect of bariatric surgery on fracture reported contradicting results

Moreover, all previous studies were underpowered to properly assess fracture sites

\section{WHAT THIS STUDY ADDS}

Severely obese patients undergoing bariatric surgery are at increased risk of fracture before surgery compared with obese and non-obese controls, and this risk remains higher after surgery

Fracture risk is site specific and changes from a pattern associated with obesity to a pattern typical of osteoporosis after surgery

Fracture risk assessment and management should be part of bariatric care

of distal lower limb fracture was higher, upper limb fracture risk was lower, and risk of clinical spine, hip, femur, or pelvic fractures was similar in the bariatric and obese groups compared with the non-obese group. After surgery, risk of distal lower limb fracture decreased (relative risk $0.66,0.56$ to 0.78 ), whereas risk of upper limb $(1.64,1.40$ to 1.93$)$, clinical spine $(1.78,1.08$ to 2.93), pelvic, hip, or femur $(2.52,1.78$ to 3.59$)$ fractures increased. The increase in risk of fracture reached significance only for biliopancreatic diversion.

\section{CONCLUSIONS}

Patients undergoing bariatric surgery were more likely to have fractures than were obese or non-obese controls, and this risk remained higher after surgery. Fracture risk was site specific, changing from a pattern associated with obesity to a pattern typical of osteoporosis after surgery. Only biliopancreatic diversion was clearly associated with fracture risk; however, results for Roux-en-Y gastric bypass and sleeve gastrectomy remain inconclusive. Fracture risk assessment and management should be part of bariatric care.

\section{Introduction}

Obesity is reaching epidemic proportions in developed countries. As bariatric surgery is effective in inducing weight loss and reducing comorbidities associated with obesity, it is being increasingly used in several countries. ${ }^{1}$ A concern is that bariatric surgery may adversely affect bone health by increasing bone resorption markers, ${ }^{2-4}$ reducing bone mineral density, ${ }^{5}$ and altering bone histomorphometry parameters. ${ }^{6-8}$ Despite this, only three studies have looked at its effect on risk of fracture and results are contradictory. ${ }^{9-11}$ Moreover, the baseline risk of fracture in severely obese patients undergoing bariatric surgery has not been determined, the effect of bariatric surgery on fracture sites has not been established owing to insufficient study power, and whether fracture risk differs by type of bariatric procedure remains unclear. Therefore, larger studies exploring the risk of fracture before and after bariatric surgery are needed. This question is very important, as it may lead to a change in the preoperative and postoperative management of these patients. It may also stimulate the development of preventive and therapeutic strategies to minimize the effect of this procedure on bone.

This study aimed to evaluate the effect of obesity and bariatric procedures on risk and sites of fracture in severely obese patients who underwent bariatric surgery compared with age and sex matched obese and non-obese controls. We hypothesized that severely obese patients undergoing bariatric surgery would be at increased risk of fracture before surgery owing to 
their higher degree of obesity, which could predispose to falls as well as to diseases (such as type 2 diabetes) and abnormalities in mineral metabolism (such as vitamin D deficiency and secondary hyperparathyroidism) that are associated with impaired bone health; ${ }^{12-15}$ that fracture risk would be higher after surgery owing to altered bone metabolism resulting from weight loss and from anatomical changes induced by surgery (such as nutrient deficiencies);2316-18 that fracture sites would change after surgery, favoring cortical sites owing to the high prevalence of secondary hyperparathyroidism after surgery and also the hip owing to the massive weight loss induced by bariatric surgery; ${ }^{19-21}$ and that bariatric procedures that include a malabsorptive component would have a more unfavorable effect on fracture risk than purely restrictive procedures, owing to their higher risk of inducing deficiencies in nutrients that are important for bone health. ${ }^{2223}$

\section{Methods}

Study design and data sources

We did a retrospective, nested case-control study in the province of Quebec, Canada, between 2001 and 2014, using administrative databases from the Quebec Integrated Chronic Diseases Surveillance System (QICDSS). ${ }^{24}$ The QICDSS links five population based healthcare administrative databases that contain information related to the management of the public health insurance programs covering the health services offered to all residents. The QICDSS contains information on 95.3\% of the Quebec population, ${ }^{24}$ and its creation has been approved by the government agencies with legal management of these databases, the Research Ethics Board of public health, and the Commission d'accès à l'information.

For this study, we used the health insurance registry (FIPA), hospital discharges (Med-Echo), and physician billing claims (PCD) databases. FIPA contains demographic information as well as data about the eligibility and admissibility of individuals to health insurance programs. Med-Echo includes information related to hospital admissions (date of admission, length of stay, diagnoses and comorbidities at admission, all hospital care provided, destination at discharge). Diagnoses are coded using 16 diagnostic codes from ICD-9-CM (international classification of diseases, ninth revision, clinical modification) before 1 April 2006 and 26 diagnostic codes from ICD-10-CA (international classification of diseases, 10th revision, Canada) thereafter. Therapeutic interventions were recorded using the Canadian Classification of Diagnostic, Therapeutic, and Surgical procedures (CCP with ICD-9-CM) and the Canadian Classification of Interventions (CCI with ICD-10-CM). Finally, PCD contains information related to physicians' reimbursement (medical service billing codes for the clinical services, dates and locations of the clinical services provided, and ICD-9-CM diagnosis codes).

\section{Identification of cohorts}

We combined diagnostic, therapeutic, and medical service billing codes to construct three groups: a group of severely obese patients who had undergone bariatric surgery (bariatric group), a control group of obese people who did not undergo bariatric surgery (obese group), and a control group of non-obese people (nonobese group). To be in the bariatric group, patients had to have a medical service billing code (PCD) associated with any bariatric surgery accompanied by a diagnostic code of obesity, a hospital admission (Med-Echo) within 30 days of the billing code with a primary or secondary diagnostic code of obesity, and an intervention code from the CCP/CCI associated with bariatric surgery during the hospital admission. We defined the index date as the date of the medical service billing code related to the surgery (see appendix 1 for codes). We paired the cohort of bariatric patients in a one to three ratio with obese people and in a one to 10 ratio with non-obese people of the same age ( \pm 3 years) and sex. The following conditions were required for people to be in the obese group: at least three medical service claims associated with a diagnostic code of obesity on different dates but within two years; at least one of these claims had to appear within six months of the index date of their bariatric counterpart; no claim or intervention code related to bariatric surgery. To be in the non-obese group, no record of any medical service claim or hospital admission mentioning a diagnosis of obesity or bariatric surgery had to be found. Detailed information related to the type of bariatric surgery was available only after implementation of ICD-10-CA coding in the hospital discharge database in 2006. We used CCI intervention codes to define four types of bariatric surgeries: adjustable gastric banding (1.NF.78.XP, 1.NF.78.EJ, 1. NF.78.XO), sleeve gastrectomy (1.NF.78.WJ, 1.NF.78.GB), Roux-en-Y gastric bypass (1.NF.78.SH, 1.NF.78.DQ), and biliopancreatic diversion (1.NF.78.SJ, 1.NF.78.DO, 1. NF.78.SI, 1.NF.78.DI) (see appendix 1 for details).

\section{Fracture outcomes}

The primary endpoint was the occurrence of a fracture. To identify fracture events and sites, we used a previously developed and validated algorithm that uses PCD. ${ }^{16}$ The algorithm was designed to first select all medical service billing codes potentially associated with fracture treatment: claims with medical service billing codes definitively related to fracture care (that is, open or closed reduction) or claims with medical service billing codes not limited to fracture care (that is, immobilization, consultation, principal or follow-up visit with an orthopedic surgeon, emergency physician, or general practitioner) if they were combined with ICD-9-CM diagnostic codes of fracture. The algorithm considered an incident fracture to have occurred if there was at least one claim associated with fracture treatment (open reduction, closed reduction, immobilization), principal visit to an orthopedic surgeon with at least one other claim, or consultation with an orthopedic surgeon with at least one other claim. We referred to the claim allowing identification of fracture as the "index claim."

We defined fracture sites by the specific medical service code of the index claim related to the treatment of fracture or, if not specific to the treatment of fracture, to 
the ICD-9-CM code. To establish the complete temporal sequence of medical care for each fracture, the algorithm identified any other claim (emergency room visit, follow-up visit) related to the same anatomical site. The date of the fracture corresponded to the date of the first claim in the temporal sequence of medical care. Finally, we established a six month period as the "washout period" between two clinical sequences related to the same anatomical fracture to minimize potential misclassification of fracture follow-up as a new incident fracture. The validity of this algorithm has been evaluated and published. ${ }^{20}$ Briefly, a sensitivity and positive predictive value of at least $80 \%$ have been shown for non-vertebral fractures. Craniofacial, hand, finger, and toe fractures were excluded.

Confounding factors associated with fracture risk We assessed several potential confounding factors, including material and social deprivation, ${ }^{25}$ area of residence, fracture history, and number of comorbidities. We divided information on the area of residence into subsets (urban versus rural) ${ }^{25}$ and noted fracture history before surgery (yes/no). Finally, we used a coding algorithm developed by Quan et al to define 30 relevant Elixhauser comorbidities in administrative databases: namely, AIDS/HIV, alcohol abuse, anemia, cardiac arrhythmia, rheumatoid arthritis, coagulopathy, chronic pulmonary disease, dementia, depression, complicated and uncomplicated diabetes, drug abuse, fluid and electrolyte disorders, heart failure, complicated and uncomplicated hypertension, liver disease, lymphoma, metastatic cancer, other neurological disorders, osteoporosis, paralysis, pulmonary circulation disorders, psychoses, renal failure, hypothyroidism, solid tumor, peptic ulcer disease, valvular disease, peripheral vascular disease, and weight loss. ${ }^{26} \mathrm{We}$ selected the model adjusted for the number of comorbidities over a model that adjusted for the most prevalent and relevant comorbidities included individually (cardiovascular disease, hypertension, chronic pulmonary disease, diabetes, cancer), as it was significantly better (more appropriate according to fitting criterion; that is, lower quasi-likelihood information criterion) and more parsimonious. We considered people to have the comorbidity if there was one hospital admission or two physician claims, at least 30 days apart, recorded in the five years before the index date, excluding the 30 days before the index date. ${ }^{27}$

\section{Statistical analyses}

We used SAS Enterprise Guide, version 6.1, for analyses. We compared descriptive characteristics of the groups by using the $\chi^{2}$ test for age and sex and univariate conditional multinomial regression for other characteristics. To evaluate changes in fracture risk and pattern before and after the index date, we used crude and adjusted conditional Poisson regression models to estimate relative risks and their 95\% confidence intervals. This regression method took into account paired data and included a stratum indicator variable that considers that matched individuals come from the same cluster. As loss to follow-up and deaths were very low after the index date and similar between groups, censure rates were very low and did not affect the results. We preferred Poisson regression models over survival models, as they consider all fractures sustained by an individual during each period. Within each group, we compared fracture rates before and after the index date by using adjusted Poisson regression models for clustered data. The observations were not completely independent in this analysis, as the same individuals were compared before and after their index date (repeated measures).

As time to first fracture is also important after bariatric surgery to evaluate whether fracture risk was growing more rapidly in the bariatric group than in the control groups, we used life table methods to compare survival curves and hazard functions between groups for the period after bariatric surgery (or the index date). In this analysis, we analyzed the time between the index date and the first of the following events: time to first fracture (event of interest), death (censored), loss to follow-up (censored), and end of study (censored). Survival curves and hazard functions were not adjusted for potential confounding factors. Lastly, we did a subgroup analysis on fracture risk by type of bariatric surgery in patients who had undergone bariatric surgery since 2006. As results were similar when we analyzed sexes separately, only data for the entire group are presented.

\section{Patient involvement}

No patients were involved in setting the research question or the outcome measures, nor were they involved in developing plans for design of the study. No patients were asked to advise on interpretation or writing up of results. There are no plans to disseminate the results of the research to study participants or the relevant patient community.

\section{Results}

\section{Baseline characteristics of groups}

Between 1 April 2001 and 31 March 2014, we identified 12676 severely obese people who had undergone bariatric surgery; 9169 (72.3\%) were women, and the mean age was 42.6 (SD 11.1) years (table 1). The obese and non-obese groups were composed of 38028 and 126760 age and sex matched people, respectively. Bariatric patients were more likely to come from small cities and rural areas, to be materially and socially disadvantaged, and to have a history of fracture compared with people in both control groups. Moreover, the proportion of patients with three or more comorbidities in the five years before their index date was higher in the bariatric group than in the control groups. People in the bariatric group were more likely to have cardiovascular disease, hypertension, chronic pulmonary disease, diabetes, hypothyroidism, renal failure, and depression but less likely to be diagnosed as having osteoporosis.

\section{Comparison of overall fracture risk between groups by period}

Before surgery, $1326(10.5 \%)$ patients in the bariatric group had at least one fracture compared with 3065 


\begin{tabular}{|c|c|c|c|c|}
\hline Characteristics & Bariatric $(n=12676)$ & Obese $(n=38028)$ & Non-obese $(n=126760)$ & Pvalue* \\
\hline Women & $9169(72.3)$ & $27507(72.3)$ & $91680(72.3)$ & 1.00 \\
\hline Mean (SD) age, years & $42.6(11)$ & $42.7(11)$ & $42.6(11)$ & 0.22 \\
\hline \multicolumn{5}{|l|}{ Area of residence: } \\
\hline Montreal census metropolitan area & $4653(36.7)$ & $20647(54.3)$ & $59363(46.8)$ & \multirow{4}{*}{$<0.001$} \\
\hline Other census metropolitan area ( $\geq 100000$ inhabitants) & $2556(20.2)$ & $8697(22.9)$ & $25672(20.3)$ & \\
\hline Census agglomeration areas (between 10000 and 100000 inhabitants) & $2472(19.5)$ & $3557(9.4)$ & $15063(11.9)$ & \\
\hline Small towns and rural areas & $2926(23.1)$ & $4994(13.1)$ & $25527(20.1)$ & \\
\hline Missing & $69(0.5)$ & $133(0.3)$ & $1135(0.9)$ & \\
\hline \multicolumn{5}{|l|}{ Fifth of material deprivationt: } \\
\hline 1 (more privileged) & $1566(12.4)$ & $7562(19.9)$ & $25473(20.1)$ & \multirow{6}{*}{$<0.001$} \\
\hline 2 & $2308(18.2)$ & $8209(21.6)$ & $25417(20.1)$ & \\
\hline 3 & $2578(20.3)$ & 7867 (20.7) & $24402(19.3)$ & \\
\hline 4 & $2839(22.4)$ & $7265(19.1)$ & $23883(18.8)$ & \\
\hline 5 (more disadvantaged) & $2920(23.0)$ & 5937 (15.6) & $22570(17.8)$ & \\
\hline Missing & $465(3.7)$ & $1188(3.1)$ & $5015(4.0)$ & \\
\hline \multicolumn{5}{|l|}{ Fifth of social deprivationt: } \\
\hline 1 (more privileged) & $2362(18.6)$ & $7809(20.5)$ & $25342(20.0)$ & \multirow{5}{*}{$<0.001$} \\
\hline 2 & $2408(19.0)$ & $7483(19.7)$ & $25369(20.0)$ & \\
\hline 3 & $2548(20.1)$ & $7444(19.6)$ & $24580(19.4)$ & \\
\hline 4 & $2408(19.0)$ & $7337(19.3)$ & 23614 (18.6) & \\
\hline 5 (more disadvantaged) & $2485(19.6)$ & $6767(17.8)$ & $22840(18.0)$ & \\
\hline Missing & $465(3.7)$ & $1188(3.1)$ & $5015(4.0)$ & \\
\hline History of fracture (before index date) & $1326(10.5)$ & $3065(8.1)$ & $8329(6.6)$ & $<0.001$ \\
\hline \multicolumn{5}{|l|}{ No of comorbiditiesł: } \\
\hline None & $3886(30.7)$ & $20549(54.0)$ & $86039(67.9)$ & \multirow{3}{*}{$<0.001$} \\
\hline $1-2$ & $6949(54.8)$ & $15455(40.6)$ & $37785(29.8)$ & \\
\hline$\geq 3$ & $1841(14.5)$ & $2024(5.3)$ & $2936(2.3)$ & \\
\hline \multicolumn{5}{|l|}{ Type of comorbidities (most prevalent)‡: } \\
\hline Cardiovascular disease§ & $873(6.9)$ & $1389(3.7)$ & $2921(2.3)$ & $<0.001$ \\
\hline Hypertension & $3757(29.6)$ & $5798(15.2)$ & $9411(7.4)$ & $<0.001$ \\
\hline Chronic pulmonary disease & $2452(19.3)$ & $4136(10.9)$ & $7867(6.2)$ & $<0.001$ \\
\hline Diabetes & $3950(31.2)$ & $3129(8.2)$ & $4117(3.2)$ & $<0.001$ \\
\hline Hypothyroidism & $799(6.3)$ & $2080(5.5)$ & $4488(3.5)$ & $<0.001$ \\
\hline Renal failure & $157(1.2)$ & $131(0.3)$ & $280(0.2)$ & $<0.001$ \\
\hline Depression & 2775 (21.9) & $5542(14.6)$ & $12650(10.0)$ & $<0.001$ \\
\hline Osteoporosis & $65(0.5)$ & $485(1.3)$ & $1819(1.4)$ & $<0.001$ \\
\hline
\end{tabular}

Table 2 | Relative risks of fracture between groups by period

\begin{tabular}{|c|c|c|c|c|c|c|}
\hline \multirow[b]{2}{*}{ Groups } & \multicolumn{3}{|c|}{ Period before surgery (or index date) } & \multicolumn{3}{|c|}{ Period after surgery (or index date) } \\
\hline & $\begin{array}{l}\text { No (\%) with } \\
\text { fractures }\end{array}$ & $\begin{array}{l}\text { Unadjusted RR } \\
(95 \% \mathrm{Cl})\end{array}$ & $\begin{array}{l}\text { Adjusted RR* } \\
(95 \% \mathrm{Cl})\end{array}$ & $\begin{array}{l}\text { No (\%) with } \\
\text { fractures }\end{array}$ & $\begin{array}{l}\text { Unadjusted RR } \\
(95 \% \mathrm{Cl})\end{array}$ & $\begin{array}{l}\text { Adjusted RR* } \\
(95 \% \mathrm{Cl})\end{array}$ \\
\hline Bariatric group $(n=12676)$ & $1326(10.5)$ & 1.65 (1.55 to 1.76$)$ & 1.30 (1.21 to 1.39$)$ & $514(4.1)$ & 1.85 (1.68 to 2.04$)$ & 1.44 (1.29 to 1.59$)$ \\
\hline Obese group $(\mathrm{n}=38028)$ & $3065(8.1)$ & $1.22(1.17$ to 1.27$)$ & $1.18(1.13$ to 1.23$)$ & $1013(2.7)$ & $1.13(1.04$ to 1.21$)$ & 1.04 (0.96 to 1.12$)$ \\
\hline Non-obese group $(n=126760)$ & $8329(6.6)$ & Reference & Reference & $3008(2.4)$ & Reference & Reference \\
\hline Pvaluet & - & $<0.001$ & $<0.001$ & - & $<0.001$ & $<0.001$ \\
\hline
\end{tabular}

$\mathrm{RR}=$ relative risk.

$<0.001<0.001$

(8.1\%) obese and 8329 (6.6\%) non-obese controls (table 2). After adjustment, risk of fracture was significantly higher in the bariatric (relative risk 1.30, 95\% confidence interval 1.21 to 1.39 ) and obese groups (1.18, 1.13 to 1.23), compared with the non-obese group. After a mean follow-up of 4.4 (range $<1-13$ ) years, bariatric patients were more likely to have sustained at least one fracture $(n=514 ; 4.1 \%)$ compared with the obese $(n=1013 ; 2.7 \%)$ and the non-obese $(n=3008 ; 2.4 \%)$ groups, with a median time to first fracture of 3.9 (interquartile range 1.6-5.8) years. Postoperative adjusted fracture risk was significantly higher in the bariatric group compared with the non-obese group (relative risk $1.44,1.29$ to 1.59$)$. Fracture risk was also significantly 


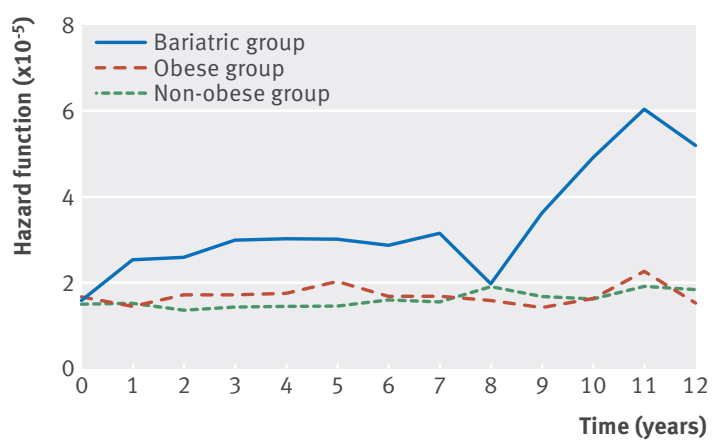

Fig 1 | Hazard function representing non-adjusted fracture risk over time for each group

higher in the bariatric group than in the obese group (relative risk 1.38, 1.23 to 1.55; data not shown in tables). Fracture risk over time remained relatively stable for both control groups whereas it increased as early as year one postoperatively in the bariatric group, reaching a first peak at year three and then plateauing, and started to rise again at year eight, reaching a second higher peak at year 11 (fig 1). The number of patients decreased over time in the bariatric group, with 2119 remaining at year 8 and 518 at year 11 .

\section{Comparison of fracture risk between groups by site and period}

Table 3 shows the distribution of fracture sites by group before and after surgery. Before surgery, the proportion of distal lower limb fractures was higher and the proportion of upper limb fractures was lower with the level of obesity. The proportion of clinical spine, hip, femur, and pelvic fractures was similar between groups. After surgery, the proportion of distal lower limb fracture almost halved in the bariatric group (from $64.2 \%$ to $37.5 \%$ ). On the other hand, the proportion of upper limb fracture increased (from $28.3 \%$ to $46.1 \%$ ), and the proportion of pelvic, hip, and femur fracture tripled (from $4.5 \%$ to $12.2 \%)$, being higher than in the obese $(7.2 \%)$ and the non-obese $(7.3 \%)$ groups.

Table 4 shows relative risks of fracture between groups by fracture site and period. Before surgery, the bariatric and obese groups had a significantly higher risk of sustaining a distal lower limb fracture (relative risk 1.71 (1.57 to 1.85 ) and 1.43 (1.35 to 1.52$)$, respectively), whereas their risk of having an upper limb fracture was lower (0.89 (0.80 to 1.00) and 0.93 (0.87 to $1.00)$, respectively) than the non-obese group. The risk of clinical spine, pelvic, hip, and femur fractures was similar between groups. After surgery, the risk of sustaining a distal lower limb fracture in the bariatric group was still slightly higher than in the non-obese group, although this was no longer statistically significant (relative risk 1.15, 0.98 to 1.35). The risks of upper limb (relative risk 1.65, 1.42 to 1.91), clinical spine (1.70, 1.06 to 2.73 ), and pelvic, hip, and femur fractures (1.88, 1.37 to 2.58 ) were all higher in the bariatric group compared with the non-obese group. Fracture risk in both control groups remained relatively stable for all sites before and after the index date, except for a decrease in distal lower limb fracture in the obese group and an increase in pelvic, hip, and femur fracture in the nonobese group (fig 2). In the bariatric group, the adjusted risk of having a distal lower limb fracture decreased (relative risk $0.66,0.56$ to 0.78 ), whereas the risk of upper limb and clinical spine fracture almost doubled and the risk of pelvic, hip, or femur fractures increased 2.5-fold after surgery (fig 2). Figure 3 shows non-adjusted fracture-free survival rates by fracture site for each group.

\section{Comparison of fracture risk by type of bariatric procedure}

Between 2006 and 2014, 9300 bariatric surgeries were performed. During this period, the annual number of surgeries increased greatly from 259 in 2006 to 1945 in 2013, and a change in practice occurred. In 2006 mixed restrictive and malabsorptive procedures (Roux-en-Y gastric bypass and biliopancreatic diversion) represented about two thirds of the surgeries, and the other third was adjustable gastric banding. In 2013 restrictive procedures (sleeve gastrectomy and adjustable gastric banding) represented the great majority of surgeries (80\%), and biliopancreatic diversion and Roux-en-Y gastric bypass were performed less frequently $(10 \%$ each). This change is explained by the arrival of sleeve gastrectomy in 2009; since then, it has gained in popularity and represented half of the surgeries in 2013. The proportion of adjustable gastric banding increased initially from $37.5 \%$ in 2006 to $50.2 \%$ in 2009 and then decreased to $28.1 \%$ in 2013 . The proportion of biliopancreatic diversion decreased from $46.3 \%$ in 2006 to $10.9 \%$ in 2013, whereas the proportion of Roux-en-Y gastric bypass remained relatively stable between $6 \%$ and $16 \%$.

Appendix 2 gives characteristics of patients undergoing the different types of bariatric surgeries. Patients undergoing sleeve gastrectomy were older and were more likely to be men, to be materially disadvantaged,

\begin{tabular}{|c|c|c|c|c|c|c|}
\hline \multirow[b]{2}{*}{ Fracture sites } & \multicolumn{3}{|c|}{ Period before surgery (or index date) } & \multicolumn{3}{|c|}{ Period after surgery (or index date) } \\
\hline & $\begin{array}{l}\text { Bariatric } \\
(n=12676)\end{array}$ & $\begin{array}{l}\text { Obese } \\
(\mathrm{n}=38028)\end{array}$ & $\begin{array}{l}\text { Non-obese } \\
(\mathrm{n}=126760)\end{array}$ & $\begin{array}{l}\text { Bariatric } \\
(n=12676)\end{array}$ & $\begin{array}{l}\text { Obese } \\
(\mathrm{n}=38028)\end{array}$ & $\begin{array}{l}\text { Non-obese } \\
(n=126760)\end{array}$ \\
\hline All fractures & 1639 & 3630 & 9760 & 621 & 1145 & 3375 \\
\hline Distal lower limb (knee, foot, ankle, and tibia/fibula) & $1053(64.2)$ & $2149(59.2)$ & $4800(49.2)$ & $233(37.5)$ & $625(54.6)$ & $1585(47.0)$ \\
\hline Clinical spine & $49(3.0)$ & $107(2.9)$ & $367(3.8)$ & $26(4.2)$ & $39(3.4)$ & $124(3.7)$ \\
\hline Pelvis, hip, and femur & $73(4.5)$ & $151(4.2)$ & $426(4.4)$ & $76(12.2)$ & $83(7.2)$ & $247(7.3)$ \\
\hline Upper limb (shoulder, humerus, elbow, forearm, and wrist) & $464(28.3)$ & $1223(33.7)$ & $4167(42.7)$ & $286(46.1)$ & $398(34.8)$ & $1419(42.0)$ \\
\hline
\end{tabular}




\begin{tabular}{|c|c|c|c|c|}
\hline \multirow[b]{2}{*}{ Groups } & \multicolumn{2}{|c|}{ Period before surgery (or index date) } & \multicolumn{2}{|c|}{ Period after surgery (or index date) } \\
\hline & Unadjusted RR $(95 \% \mathrm{Cl})$ & Adjusted RR* $(95 \% \mathrm{Cl})$ & Unadjusted RR $(95 \% \mathrm{CI})$ & Adjusted $R^{*}(95 \% \mathrm{Cl})$ \\
\hline \multicolumn{5}{|c|}{ Distal lower limb (knee, foot, ankle, and tibia/fibula) } \\
\hline Bariatric group $(n=12676)$ & 2.15 (1.99 to 2.32$)$ & 1.71 (1.57 to 1.85$)$ & $1.47(1.26$ to 1.72$)$ & 1.15 (0.98 to 1.35$)$ \\
\hline Obese group $(n=38028)$ & $1.46(1.38$ to 1.55$)$ & $1.43(1.35$ to 1.52$)$ & $1.30(1.18$ to 1.44$)$ & 1.21 (1.09 to 1.34) \\
\hline Non-obese group $(n=126760)$ & Reference & Reference & Reference & Reference \\
\hline P valuet & $<0.001$ & $<0.001$ & $<0.001$ & 0.001 \\
\hline \multicolumn{5}{|l|}{ Clinical spine } \\
\hline Bariatric group $(n=12676)$ & $1.33(0.97$ to 1.82$)$ & 0.81 (0.58 to 1.13) & 2.14 (1.40 to 3.28$)$ & 1.70 (1.06 to 2.73$)$ \\
\hline Obese group $(n=38028)$ & $0.96(0.77$ to 1.20$)$ & 0.88 (0.70 to 1.11$)$ & $1.03(0.70$ to 1.52$)$ & $1.00(0.68$ to 1.49$)$ \\
\hline Non-obese group $(n=126760)$ & Reference & Reference & Reference & Reference \\
\hline P valuet & 0.25 & 0.31 & 0.03 & 0.15 \\
\hline \multicolumn{5}{|l|}{ Pelvis, hip, and femur } \\
\hline Bariatric group $(n=12676)$ & $1.76(1.30$ to 2.38$)$ & 1.08 (0.78 to 1.49$)$ & $3.12(2.35$ to 4.14$)$ & 1.88 (1.37 to 2.58$)$ \\
\hline Obese group $(n=38028)$ & $1.16(0.94$ to 1.44$)$ & $1.05(0.84$ to 1.31$)$ & $1.11(0.84$ to 1.47$)$ & $0.90(0.67$ to 1.21$)$ \\
\hline Non-obese group $(n=126760)$ & Reference & Reference & Reference & Reference \\
\hline Pvaluet & 0.009 & 0.84 & $<0.001$ & 0.001 \\
\hline \multicolumn{5}{|c|}{ Upper limb (shoulder, humerus, elbow, forearm, and wrist) } \\
\hline Bariatric group $(n=12676)$ & 1.11 (1.00 to 1.23$)$ & 0.89 (0.80 to 1.00$)$ & $2.03(1.77$ to 2.34$)$ & $1.65(1.42$ to 1.91$)$ \\
\hline Obese group $(n=38028)$ & $0.96(0.90$ to 1.03$)$ & $0.93(0.87$ to 1.00$)$ & 0.95 (0.84 to 1.08$)$ & 0.90 (0.80 to 1.02) \\
\hline Non-obese group $(n=126760)$ & Reference & Reference & Reference & Reference \\
\hline Pvaluet & 0.07 & 0.04 & $<0.001$ & $<0.001$ \\
\hline
\end{tabular}

\begin{tabular}{|c|c|c|}
\hline $\begin{array}{l}\text { Fracture type } \\
\text { All }\end{array}$ & $\begin{array}{l}\text { Adjusted relative } \\
\text { risk }(95 \% \mathrm{Cl})\end{array}$ & $\begin{array}{l}\text { Adjusted relative } \\
\text { risk }(95 \% \mathrm{Cl})\end{array}$ \\
\hline Non-obese group & - & 1.04 (0.99 to 1.09$)$ \\
\hline Obese group & $=$ & 0.88 (0.82 to 0.95$)$ \\
\hline Bariatric group & $=$ & $1.08(0.97$ to 1.21$)$ \\
\hline \multicolumn{3}{|l|}{ Distal lower limb } \\
\hline Non-obese group & - & $1.00(0.93$ to 1.06$)$ \\
\hline Obese group & - & $0.82(0.75$ to 0.91$)$ \\
\hline Bariatric group & - & 0.66 (0.56 to 0.78$)$ \\
\hline \multicolumn{3}{|l|}{ Clinical spine } \\
\hline Non-obese group & $=$ & 1.03 (0.83 to 1.18 ) \\
\hline Obese group & & 1.01 (0.67 to 1.52 ) \\
\hline Bariatric group & $\rightarrow$ & 1.78 (1.08 to 2.93$)$ \\
\hline \multicolumn{3}{|l|}{ Pelvis, hip, and femur } \\
\hline Non-obese group & - & 1.49 (1.24 to 1.78$)$ \\
\hline Obese group & - & 1.29 (0.97 to 1.72$)$ \\
\hline Bariatric group & $\rightarrow$ & 2.52 (1.78 to 3.59 ) \\
\hline \multicolumn{3}{|l|}{ Upper limb } \\
\hline Non-obese group & $=$ & 1.04 (0.97 to 1.11$)$ \\
\hline Obese group & - & 0.93 (0.82 to 1.05$)$ \\
\hline Bariatric group & - & 1.64 (1.40 to 1.93$)$ \\
\hline
\end{tabular}

Fig 2 | Change in fracture risk after versus before surgery (or index date) within each group for all fractures and by fracture site. Data are presented as relative risk $(95 \% \mathrm{Cl})$ adjusted for duration of follow-up, age in middle of period, material and social deprivation, area of residence, history of fracture, and number of comorbidities in previous five years, using multivariate Poisson regression model for clustered data

and to have comorbidities including cardiovascular disease and renal failure. Patients undergoing Roux-en-Y gastric bypass were more likely to be socially disadvantaged and to have comorbidities but less likely to have a history of fracture. Patients undergoing biliopancreatic diversion were less likely to come from metropolitan area and to have a history of fracture or depression. Before surgery, adjusted fracture risks in the surgery groups were all significantly higher than in the non-obese group, except for Roux-en-Y gastric bypass (table 5). After surgery, only biliopancreatic diversion was clearly associated with an increased risk of fracture (adjusted relative risk 1.60, 1.25 to 2.03). Figure 4 shows fracture-free survival rates by type of bariatric surgery.

\section{Discussion}

In this large study representative of patients undergoing bariatric surgery in Quebec, mainly women in their early 40s, we showed that severely obese people undergoing surgery are at increased risk of fracture compared with obese and non-obese controls and that their risk remains higher after surgery. Our study highlighted for the first time that risk of fracture is site specific and changes from a pattern associated with obesity (higher susceptibility for distal lower limb fracture and lower susceptibility for upper limb fracture) to a pattern in which risk of lower limb fracture is reduced but risk of fracture at sites typical of osteoporosis is increased (upper limb, clinical spine, pelvis, hip, femur). ${ }^{28}$ Furthermore, only biliopancreatic diversion, a mixed malabsorptive and restrictive procedure, was clearly associated with an increased risk of fracture. However, fracture risk associated with sleeve gastrectomy and Roux-en-Y gastric bypass remains inconclusive owing to the small number of cases for Roux-en-Y gastric bypass ( $\mathrm{n}=873$; median follow-up of 2.7 years) and the short fol- 

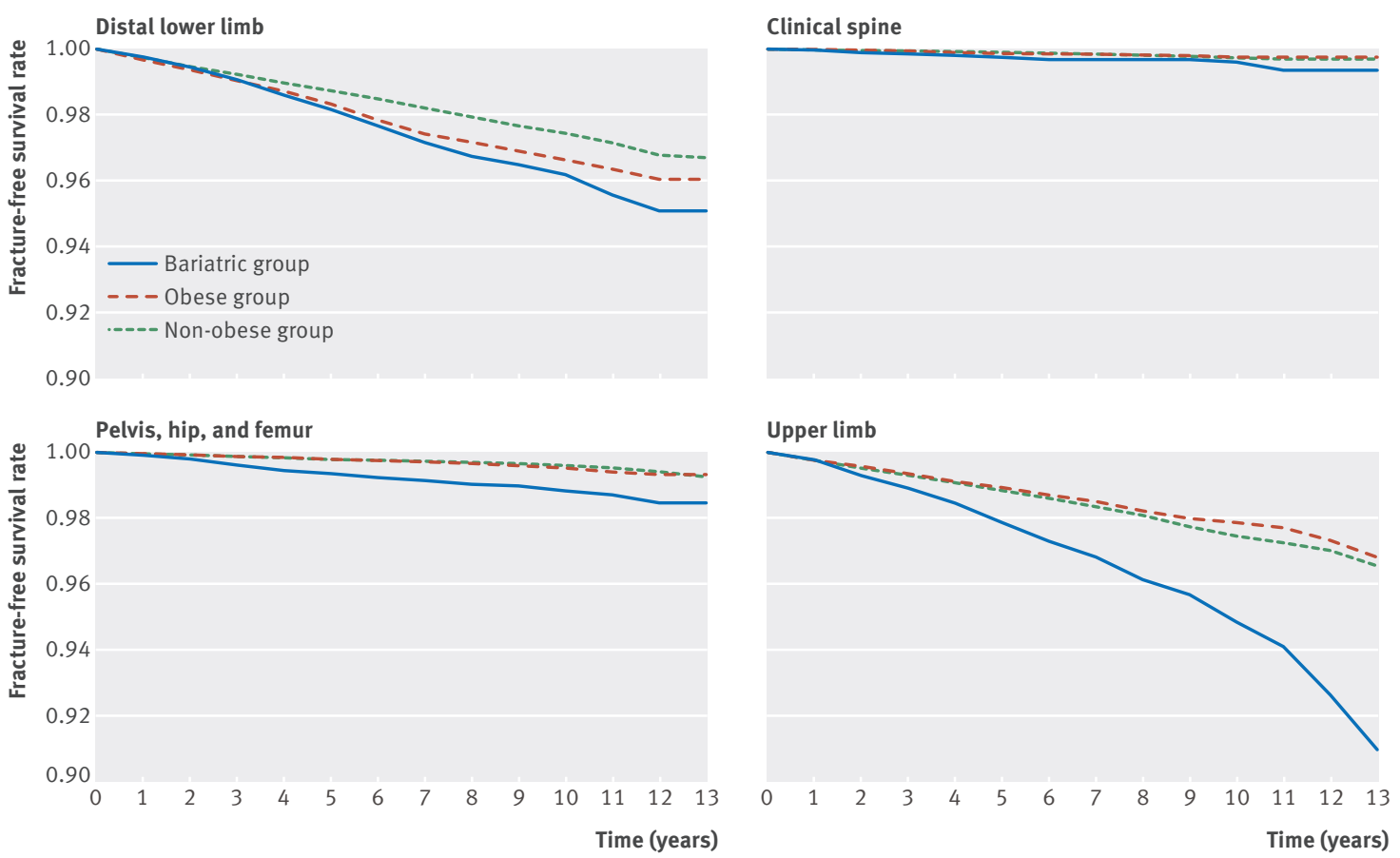

Fig 3 | Non-adjusted fracture-free survival rate by site and by group

low-up for sleeve gastrectomy (median follow-up of 1.3 years).

\section{Comparison with other studies}

To our knowledge, only three studies have examined risk of fracture after bariatric surgery. In a retrospective review of medical files from a single Minnesota hospital including 258 Caucasian patients ( $82 \%$ women; mean age 43.6 years), Nakamura et al showed that fracture risk doubled after Roux-en-Y gastric bypass compared with age and sex matched people from the general US population, after adjustment for physical activity, malnutrition, smoking, alcohol consumption, and fracture history, but not for body mass index. ${ }^{9}$ The results of this study are difficult to compare with ours, as Roux-en-Y gastric bypass was underrepresented in our study, precluding us from drawing firm conclusions on fracture risk associated with this procedure. Nevertheless, our study showed that another mixed malabsorptive and restrictive procedure, biliopancreatic diversion, was associated with an increased risk of fracture. The first fracture occurred much earlier in our study (mean of $3.9 v 13$ years). This may be due to a higher baseline fracture risk in our population, a shorter follow-up, different surgery types, or postoperative management protocols. Lu et al showed that fracture risk was 1.2 times higher after bariatric surgery in 2064 Thai patients (64\% women; mean age 31.8 years) compared with 5027 propensity score matched controls followed for a mean of 4.8 years. ${ }^{11} \mathrm{~A}$ higher risk of fracture was restricted to malabsorptive procedures (high gastric bypass and gastroenterostomy), which is in line with our findings. On the other hand, Lalmohamed et al compared fracture risk between 2079 patients ( $84 \%$ women; mean age 44.6 years) undergoing adjustable gastric banding (60\%) and Roux-en-Y gastric bypass (29\%) and 10442 controls matched for age, sex, and body mass index. ${ }^{10}$ No change in fracture risk following surgery was seen after a mean follow-up of 2.2 years, but there was a trend for an increased risk after three to five years, after adjustment for smoking, falls, fractures, chronic diseases, and drugs. The short follow-up, the small

Table 5 | Relative risks of fracture by type of bariatric procedure (for period between 2006 and 2014)

\begin{tabular}{|c|c|c|c|c|c|c|c|c|}
\hline \multirow[b]{2}{*}{ Groups } & \multicolumn{4}{|c|}{ Period before surgery (or index date) } & \multicolumn{4}{|c|}{ Period after surgery (or index date) } \\
\hline & $\begin{array}{l}\text { No (\%) with } \\
\text { fractures }\end{array}$ & $\begin{array}{l}\text { Unadjusted RR } \\
(95 \% \mathrm{Cl})\end{array}$ & $\begin{array}{l}\text { Adjusted RR* } \\
(95 \% \mathrm{Cl})\end{array}$ & $P$ value & $\begin{array}{l}\text { No (\%) with } \\
\text { fractures }\end{array}$ & $\begin{array}{l}\text { Unadjusted RR } \\
(95 \% \mathrm{Cl})\end{array}$ & $\begin{array}{l}\text { Adjusted RR* } \\
(95 \% \mathrm{Cl})\end{array}$ & $P$ value \\
\hline Adjustable gastric banding $(n=3887)$ & $467(12.0)$ & 1.83 (1.65 to 2.04$)$ & 1.50 (1.34 to 1.68$)$ & $<0.001$ & $80(2.1)$ & $1.43(1.10$ to 1.86$)$ & 1.08 (0.83 to 1.39$)$ & 0.58 \\
\hline Sleeve gastrectomy $(n=2554)$ & $310(12.1)$ & 1.50 (1.32 to 1.71$)$ & 1.16 (1.01 to 1.33$)$ & 0.04 & $35(1.4)$ & $1.76(1.17$ to 2.64$)$ & 1.27 (0.86 to 1.88$)$ & 0.23 \\
\hline Roux-en-Y gastric bypass $(n=873)$ & $99(11.3)$ & 1.64 (1.32 to 2.04$)$ & 1.17 (0.91 to 1.51$)$ & 0.23 & $23(2.6)$ & 1.54 (0.96 to 2.46$)$ & $1.13(0.67$ to 1.92$)$ & 0.65 \\
\hline Biliopancreatic diversion $(n=1986)$ & $212(10.7)$ & 1.61 (1.38 to 1.88$)$ & 1.20 (1.01 to 1.42$)$ & 0.04 & $94(4.7)$ & 2.26 (1.81 to 2.83$)$ & 1.60 (1.25 to 2.03$)$ & $<0.001$ \\
\hline Obese group $(\mathrm{n}=27900)$ & $2463(8.8)$ & $1.20(1.14$ to 1.26$)$ & $1.18(1.12$ to 1.24$)$ & $<0.001$ & $514(1.8)$ & $1.21(1.09$ to 1.34$)$ & $1.12(1.00$ to 1.25$)$ & 0.004 \\
\hline Non-obese group $(\mathrm{n}=93000)$ & $6798(7.3)$ & Reference & Reference & & $1422(1.5)$ & Reference & Reference & \\
\hline
\end{tabular}




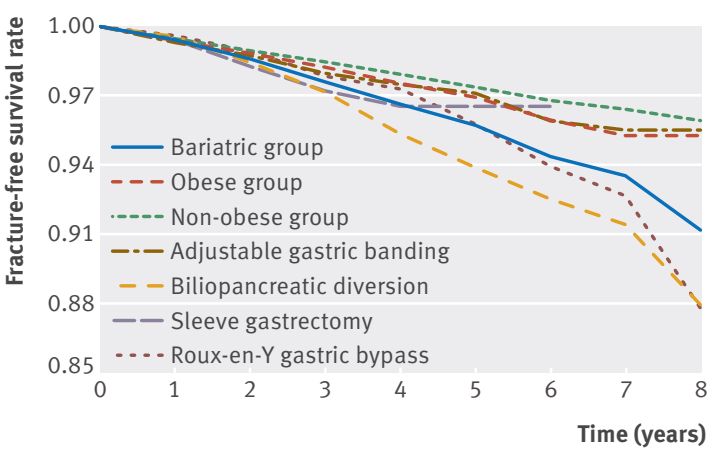

Fig 4 | Non-adjusted fracture-free survival rate (all fractures) by group and by type of bariatric procedure (for period between 2006 and 2014). Although fracture-free survival rate appears similar in adjustable gastric banding group to non-obese and obese groups, it is decreasing more rapidly in biliopancreatic diversion and Roux-en-Y gastric bypass groups. Follow-up time for sleeve gastrectomy is too short to draw conclusions

number of fractures ( $\mathrm{n}=39)$, and the use of mainly adjustable gastric banding, which, according to our findings, does not seem to have a negative effect on bone metabolism and is less likely to be performed in severely obese patients who have several comorbidities, may explain the negative findings. This is, however, the only study using a control group that was matched for body mass index.

Our study showed that a positive relation existed between the level of obesity and risk of fracture. At baseline, fracture risk was about 30\% higher in the group undergoing bariatric surgery and $18 \%$ greater in the obese group compared with the non-obese group. The degree of obesity is probably the main explanation for the difference in fracture risk observed between the obese group and the group undergoing bariatric surgery, as our groups were not matched for body mass index or for comorbidities. ${ }^{29}$ The typical body mass index in the Quebec bariatric population is around 45-50, which is likely significantly higher than that of the obese control group. ${ }^{30-32}$ Our results support recent data suggesting that obesity may not be as protective for fracture as was originally thought. Johansson et al showed, in a large meta-analysis including 398610 women, that when adjusted for bone mineral density, higher body mass index was associated with a slight but significant increase in fracture risk (hazard ratio per 1 unit increase in body mass index 1.01, 95\% confidence interval 1.01 to 1.02 ; $\mathrm{P}<0.001){ }^{33}$ These results suggest that the increase in bone mineral density seen with the increase in weight is not sufficient to protect against fractures. Another proposed explanation is that in obesity, bone quality plays a predominant role over bone quantity in decreasing bone strength. ${ }^{34}$ Prevalent factors in obesity that may affect bone strength and fracture risk include vitamin D deficiency, secondary hyperparathyroidism, subclinical chronic inflammation, type 2 diabetes, and changes in adipokines. ${ }^{1835}$ In our study, patients in the bariatric group had more comorbidities than did people in the other groups, including a higher prevalence of type 2 diabetes. However, increased fracture risk in obesity is unlikely to be explained only by the presence of comorbidities, as we adjusted for this factor in our analyses. Our study also showed that fracture risk is site specific in obesity. At baseline, patients in both the bariatric and the obese groups were at a higher risk of a distal lower limb fracture but at a lower risk of an upper limb fracture compared with the non-obese group. The risk of ankle fracture is known to increase linearly with the increase in weight (hazard ratio per $5 \mathrm{~kg}$ increase 1.05, 1.02 to $1.07 ; \mathrm{P}<0.001)^{36}$ and body mass index (relative risk per 5 unit increase 1.18, 1.12 to 1.24 ; $\mathrm{P}<0.001) .^{37}$ The increased risk in distal lower limb fracture with obesity is thought to result from the fact that the lower body has to support a greater weight. ${ }^{35}$ Regarding the lower risk of upper limb fracture with obesity, our results are difficult to compare with other studies owing to the different grouping of fracture sites. Some studies have shown an increase in risk of proximal humerus and shoulder fracture, ${ }^{33} 38$ whereas others failed to show this. ${ }^{36}$ Moreover, some but not all studies showed an increase in risk of distal forearm and wrist fracture with obesity. 333638 The lower risk of upper limb fracture observed in our study may be due to a different falls pattern in obese compared with non-obese people. ${ }^{35} 38$ Contrary to what was observed in several studies, 333738 risk of hip and femur fracture was similar between obese and non-obese people in our study, likely owing to the small number of such fractures in our relatively young population. Further studies are needed to elucidate the mechanisms explaining the site specific fracture risk in obese people.

Our study also showed for the first time that bariatric surgery seems to have deleterious effects on bone at some sites but limited effects at other sites. Whereas risk of distal lower limb fracture was reduced after surgery, the risk of upper limb, clinical spine, hip, femur, and pelvic fracture increased. The specific factors explaining the changes in fracture sites after bariatric surgery remain largely hypothetical and incompletely understood. For instance, the reduction in distal lower limb fractures after surgery may be driven by the lower weight supported by this part of the body after weight loss. However, whereas weight reduction seemed to be beneficial on the risk of distal lower limb fracture, this effect was not seen in other weight bearing sites such as the hip and pelvis, suggesting that other factors are involved. The increase in upper limb fractures may be partly explained by secondary hyperparathyroidism, which is prevalent after malabsorptive surgeries and known to affect predominantly cortical bone. ${ }^{1838-40}$ However, the fact that fracture risk at the lower limb, which is also mainly composed of cortical bone, was not increased in our study suggests that other factors play a role in the increase in risk of upper limb fracture after bariatric surgery. One hypothesis is that falls pattern changes after bariatric surgery, resulting in different fracture sites. Although no study has evaluated falls pattern in this context, prevalence of falls is high after surgery; $34 \%$ of patients reported two or more 
falls and 24\% reported balance problems five years after Roux-en-Y gastric bypass. ${ }^{41}$ Moreover, a recent randomized controlled trial comparing conventional treatment and Roux-en-Y gastric bypass for diabetes found a greater number of falls leading to fractures in the surgery group than in the conventional group after two years. ${ }^{42}$ These results may be explained by the fact that rapid weight loss often results in loss of muscle, ${ }^{43}$ which could predispose to falls. ${ }^{44}$ Finally, the change to an osteoporotic-like fracture pattern after surgery may be partly explained by the ageing of our mainly female population through follow-up, some becoming menopausal. This factor could be involved in the second peak in fracture risk observed in our study at year 11 after surgery, as the mean age of our cohort was 42 years at study entry. This second peak may also be artifactual owing to smaller sample size at this time point $(n=518)$. However, menopause is unlikely to explain the first peak in fracture risk that occurred three years after surgery.

The increase in fracture risk at sites typically seen in osteoporosis is consistent with studies showing that bone loss occurs at most osteoporotic sites after bariatric surgery-namely, the forearm, hip, femoral neck, and spine. ${ }^{2345}$ Also, markers of bone turnover, and particularly of bone resorption, increase markedly and rapidly after bariatric surgery. ${ }^{39}$ These markers stay elevated in the long term, up to 10 years after biliopancreatic diversion in one study, ${ }^{8}$ even when weight has stabilized. This increase is also seen despite adequate calcium and vitamin D supplementation and normal parathyroid hormone concentrations. ${ }^{246}$ Altogether, these results imply that other factors are involved and that the increase in bone remodeling seen after bariatric surgery is likely to be multifactorial. Several mechanisms have been proposed, but their relative importance remains unclear and likely depends on the type of bariatric procedure. Nutritional factors are probably involved, as well as factors associated with weight loss and with anatomical changes induced by surgery. One recent study showed that sclerostin concentrations, which are increased after surgery owing to mechanical unloading, correlate with the increase in bone loss at the lumbar spine, total hip, and total body. ${ }^{16}$ The effect on bone of changes in hormonal factors associated with weight loss, such as the diminution of leptin and estrogen concentrations and the increase in adiponectin concentrations, is complex and remains to be clarified in humans, especially after bariatric surgery. Reduced peripheral leptin and estrogen concentrations could lead to an increase in bone resorption. ${ }^{183947}$ On the other hand, although adiponectin decreased osteoclastogenesis and promoted osteoblastogenesis in vivo and in vitro, clinical studies showed an inverse association between adiponectin concentrations and bone mineral density. ${ }^{21718}$ Similarly, the roles of ghrelin, a hormone secreted by the stomach that promotes osteoblast function and bone formation, and gut hormones such as glucagon-like peptide 1 and peptide YY in the alteration of bone metabolism after surgery are unknown. ${ }^{318}$ Other factors such as metabolic acidosis could also be implicated in the bone loss seen after bariatric surgery by increasing urinary calcium and by activating osteoclast activity. ${ }^{4849}$ Finally, physical activity may be increased after surgery, possibly leading to more traumatic fractures.

Regarding the effect of different types of bariatric surgery on fracture risk, the results of published studies are in line with our findings. We found that biliopancreatic diversion, a mixed malabsorptive and restrictive procedure, was associated with an increased risk of fracture and that adjustable gastric banding was not.9-11 It seems plausible that surgeries that include a malabsorptive component lead to greater bone loss than do purely restrictive procedures, as they induce greater weight loss and are more likely to cause deficiencies in nutrients that are important for bone health, including calcium, vitamin D, and protein. ${ }^{232950}$ After all bariatric surgeries, especially mixed malabsorptive and restrictive procedures, clinical guidelines recommend supplementation with multivitamins, calcium, and vitamin D, ensuring adequate protein intake, and encouraging aerobic physical activity and strength training. ${ }^{51}$ However, the efficacy of these interventions relies on long term adherence, which at least for multivitamin use was reported to be poor in both adolescents and adults (30\% and 50\%, respectively). ${ }^{5253}$ Moreover, a recent survey showed that healthcare professionals who take care of bariatric patients often do not follow recommendations on multivitamin, calcium, and vitamin D supplementation. ${ }^{54}$ Unfortunately, we could not assess compliance with supplement and physical activity recommendations in our study. However, vitamin D deficiency was reported to be very low after biliopancreatic diversion in Quebec, ${ }^{55}$ so compliance with vitamin D supplements does not seem to be the main factor explaining our results, at least for this procedure. Nevertheless, our results emphasize the importance of reinforcing adherence of patients and bariatric centers to clinical guidelines. A recently published prospective interventional study showed that a multimodal approach including calcium citrate, vitamin D, and protein supplements, combined with Nordic walking (45 minutes three times a week) and strength perseverance and equipment training (30 minutes twice a week) for two years resulted in a lower decrease in lean body mass as well as in bone mineral density at the lumbar spine, hip, and femoral neck and a lower increase in bone turnover markers and parathyroid hormone in patients undergoing Roux-en-Y gastric bypass and sleeve gastrectomy. ${ }^{46}$ Although no evidence yet shows that this approach reduces fracture risk, it certainly contributes to limiting postoperative muscle and bone loss. Good quality randomized controlled trials are needed to delineate the best strategy to adopt to minimize the effect of bariatric surgery on bone. In addition, as long term benefits of bariatric surgery on reduction of comorbidities and mortality, improved quality of life, and reduced healthcare costs have been well demonstrated over the 
past 20 years, ${ }^{56-58}$ and as randomized controlled trials have confirmed the superiority of bariatric surgery over medical treatment, ${ }^{59-61}$ the risk of bone fracture after surgery must be balanced against these well described long term health benefits.

\section{Strengths and limitations of study}

Our study has several strengths. Firstly, this is one of the very few studies that have assessed the hard outcome of fracture after bariatric surgery and, most importantly, our sample size is by far the largest to date, enabling us to assess fracture risk by site. We are also confident that fractures and study groups were correctly identified, as we used a validated algorithm for fracture identification, intervention codes for bariatric surgery were repeated in both the PCD and MedEcho, and stringent criteria were established to identify obese people. Furthermore, the use of healthcare administrative databases to identify obese people has been shown to have a good positive predictive value. ${ }^{62}$

The study does, however, have limitations. The bariatric and the obese groups were not matched for body mass index, as this information was not available in the databases. This could have resulted in the group of obese controls being less obese and having fewer comorbidities than the bariatric group, which could partly explain the difference in fracture risk observed between these groups at baseline and follow-up. However, the fact that fracture sites changed after bariatric surgery suggests that the increased baseline fracture risk in the bariatric group is not the sole factor explaining the higher risk of fracture after bariatric surgery. Although we acknowledge that the impossibility of assessing body mass index in each group is an important limitation of our study, we think that both comparator groups are still valuable as they provide a gradient of obesity across the groups. In an attempt to bypass this limitation, we also compared each group with itself after versus before the index date. In addition, surgical subgroups were not necessarily comparable in terms of body mass index and comorbidities, which could partly explain differences in fracture risk among bariatric procedures. Moreover, we did not exclude patients with a history of fracture who could have had an underlying secondary cause of osteoporosis before surgery. We decided to include all patients undergoing bariatric surgery to ensure that this population was representative of the bariatric population. Previous fracture history or risk factors for osteoporosis are not contraindications for surgery, and previous history of fracture is a strong risk factor for future fracture. As such, excluding patients with a previous fracture history would exclude patients who are at high risk of fracture after bariatric surgery. In addition, only clinical spine fractures were identified in the databases, leading to an underestimation of fractures at this site. Another limitation is that the level of trauma and several important confounders that may affect bone health or risk of fracture or falls were not assessed, including drugs, physical activity, weight loss, smoking, and alcohol use. Finally, as reliable codification of bariatric procedures in Med-Echo and the PCD was not available until 2006, the follow-up for sleeve gastrectomy was short and the number of Roux-en-Y gastric bypasses was small, precluding us from drawing firm conclusions on fracture risk with these procedures. Also, the great majority of our study population had a Europid background, and results of this study may not be generalizable to other ethnic groups.

\section{Conclusions and policy implications}

In conclusion, severely obese patients undergoing bariatric surgery are more susceptible to fracture than are obese and non-obese people, and this risk remains higher after surgery. Moreover, fracture risk is site specific in this group before and after surgery. Bariatric surgery seems to have a limited effect on risk of lower limb fracture, but it seems to increase susceptibility for fracture sites typically seen in osteoporosis. Although our study suggests that biliopancreatic diversion is associated with an increased fracture risk and adjustable gastric banding is not, we could not make conclusions about fracture risk associated with sleeve gastrectomy and Roux-en-Y gastric bypass owing to short follow-up and small number of patients. To minimize the effect of bariatric surgery on bone, guidelines should be followed and the importance of adherence to supplements and physical activity should be reinforced among patients and healthcare professionals. A referral to a bone specialist should be considered in cases in which fracture risk is high before surgery or when the biochemical parameters do not normalize or a fracture occurs after surgery. Finally, it is important to weigh the benefits and risks of surgery for a given patient in order to propose the type of surgery that is best suited to the patient, as the efficacy of bariatric surgeries differs in terms of resolution of comorbidities associated with obesity. ${ }^{61}$ More studies that aim at understanding the mechanisms underlying the increased risk of fracture and at evaluating the efficacy of preventive and therapeutic strategies to reduce the effect of bariatric surgery on bone are needed given the paucity of evidence based guidelines in this area.

We are grateful to Patricia Lamontagne (Institut national de santé publique du Québec, Quebec City, Canada) and Mohsen Agharazii (CHU de Québec Research Centre, Quebec City, Canada), who provided input and helpful comments on the manuscript.

Contributors: CG and SJ had the idea for the study. CG, SJ, SL, and FM-W designed the study. SJ and PG did the statistical analyses. CG, SJ, CR, SL, PG, and FM-W interpreted the findings. CR, CG, and SJ wrote the first draft of the manuscript and revised subsequent versions. The other authors provided input, expertise, and critical review of the paper. All authors read and approved the final version of the paper. CG, SJ, and PG are the guarantors.

Funding: CR is supported by a scholarship from the Department of Medicine, Laval University and from the Fondation du CHU de Québec. CG and FM-W are supported by scholarships from the Fonds de la recherche du Québec-Santé (FRQ-S). FM-W is also supported by a scholarship from the KRESCENT program of the Kidney Foundation of Canada. 
Competing interests: All authors have completed the ICMJE uniform disclosure form at www.icmje.org/coi_disclosure.pdf (available on request from the corresponding author) and declare: no support from any organization for the submitted work; LB has received grants from Johnson and Johnson, Valen TX, and GI Windows; LM has received honorariums (speakers' fees) from Amgen, Abbvie, Eli Lilly, and Britsol Myers Squibb, as well as research equipment from Roche Diagnostics Canada; CG has been a member of advisory boards for Amgen and Eli Lilly; LB has been a member of advisory board for GI Windows; no other relationships or activities that could appear to have influenced the submitted work

Ethical approval: Not needed.

Data sharing: Additional data from the study are available from the corresponding author at claudia.gagnon@crchudequebec.ulaval.ca.

Transparency statement: The lead author affirms that this manuscript is an honest, accurate, and transparent account of the study being reported; that no important aspects of the study have been omitted; and that any discrepancies from the study as planned (and, if relevant, registered) have been explained.

This is an Open Access article distributed in accordance with the Creative Commons Attribution Non Commercial (CC BY-NC 3.0) license, which permits others to distribute, remix, adapt, build upon this work non-commercially, and license their derivative works on different terms, provided the original work is properly cited and the use is noncommercial. See: http://creativecommons.org/licenses/by-nc/3.0/.

1 Angrisani L, Santonicola A, lovino P, Formisano G, Buchwald H, Scopinaro N. Bariatric Surgery Worldwide 2013. Obes Surg 2015;25:1822-32. doi:10.1007/s11695-015-1657-z.

2 Bruno C, Fulford AD, Potts JR, et al. Serum markers of bone turnover are increased at six and 18 months after Roux-en-Y bariatric surgery: correlation with the reduction in leptin. J Clin Endocrinol Metab 2010-95:159-66. doi:10.1210/jic.2009-0265.

3 Scibora LM. Skeletal effects of bariatric surgery: examining bone loss, potential mechanisms and clinical relevance. Diabetes Obes Metab 2014;16:1204-13. doi:10.1111/dom.12363.

4 Coates PS, Fernstrom JD, Fernstrom MH, Schauer PR, Greenspan SL. Gastric bypass surgery for morbid obesity leads to an increase in bone turnover and a decrease in bone mass. J Clin Endocrinol Metab 2004;89:1061-5. doi:10.1210/jc.2003-031756.

5 Yu EW, Bouxsein ML, Putman MS, et al. Two-year changes in bone density after Roux-en-Y gastric bypass surgery. J Clin Endocrinol Metab 2015:100:1452-9 doi:10.1210/jc. 2014-4341.

6 Compston JE, Vedi S, Gianetta E, Watson G, Civalleri D, Scopinaro N. Bone histomorphometry and vitamin $\mathrm{D}$ status after biliopancreatic bypass for obesity. Gastroenterology 1984:87:350-6.

7 Parfitt AM, Pødenphant J, Villanueva AR, Frame B. Metabolic bone disease with and without osteomalacia after intestinal bypass surgery: a bone histomorphometric study. Bone 1985;6:211-20. doi:10.1016/8756-3282(85)90003-1.

8 Marceau P, Biron S, Lebel S, et al. Does bone change after biliopancreatic diversion? J Gastrointest Surg 2002;6:690-8. doi:10.1016/S1091-255X(01)00086-5.

9 Nakamura KM, Haglind EG, Clowes JA, et al. Fracture risk following bariatric surgery: a population-based study. Osteoporos Int 2014:25:151-8, doi:10.1007/s00198-013-2463-x.

10 Lalmohamed A, de Vries F, Bazelier MT, et al. Risk of fracture after bariatric surgery in the United Kingdom: population based, retrospective cohort study. BM/2012:345:e5085. doi:10.1136/bmi.e5085.

11 Lu CW, Chang YK, Chang HH, et al. Fracture Risk After Bariatric Surgery: A 12-Year Nationwide Cohort Study. Medicine (Baltimore) 2015:94:e2087 doi:101097/MD .0000000000002087.

12 Corbeil P, Simoneau M, Rancourt D, Tremblay A, Teasdale N. Increased risk for falling associated with obesity: mathematical modeling of postural control. IEEE Trans Neural Syst Rehabil Eng 2001;9:126-36. doi:10.1109/7333.928572.

13 Epstein S, Defeudis G, Manfrini S, Napoli N, Pozzilli P. Scientific Committee of the First International Symposium on Diabetes and Bone. Diabetes and disordered bone metabolism (diabetic osteodystrophy): time for recognition. Osteoporos Int 2016;27:193151. doi:10.1007/s00198-015-3454-X.

14 Grethen E, McClintock R, Gupta CE, et al. Vitamin D and hyperparathyroidism in obesity. J Clin Endocrinol Metab 2011;96:1320-6. doi:10.1210/jc.2010-2202.

15 Sánchez A, Rojas P, Basfi-Fer K, et al. Micronutrient Deficiencies in Morbidly Obese Women Prior to Bariatric Surgery. Obes Surg 2016;26:361-8. doi:10.1007/s11695-015-1773-9.

16 Muschitz C, Kocijan R, Marterer C, et al. Sclerostin levels and changes in bone metabolism after bariatric surgery. J Clin Endocrinol Metab 2015;100:891-901. doi:10.1210/jc.2014-3367.

17 Carrasco F, Ruz M, Rojas P, et al. Changes in bone mineral density, body composition and adiponectin levels in morbidly obese patients after bariatric surgery. Obes Surg 2009;19:41-6. doi:10.1007/s11695-008-9638-0.
18 Folli F, Sabowitz BN, Schwesinger W, Fanti P, Guardado-Mendoza R, Muscogiuri G. Bariatric surgery and bone disease: from clinical perspective to molecular insights. Int J Obes (Lond) 2012;36:1373-9. doi:10.1038/ijo.2012.115

19 Duan Y, De Luca V, Seeman E. Parathyroid hormone deficiency and excess: similar effects on trabecular bone but differing effects on cortical bone. J Clin Endocrinol Metab 1999;84:718-22. doi:10.1210/ jcem.84.2.5498.

20 Silverberg SJ, Shane E, de la Cruz L, et al. Skeletal disease in primary hyperparathyroidism. / Bone Miner Res 1989;4:283-91. doi:10.1002/ jbmr.5650040302.

21 Fleischer J, Stein EM, Bessler M, et al. The decline in hip bone density after gastric bypass surgery is associated with extent of weight loss. Clin Endocrinol Metab 2008;93:3735-40. doi:10.1210/jc.2008-0481.

22 Heber D, Greenway FL, Kaplan LM, Livingston E, Salvador J, Still C. Endocrine Society. Endocrine and nutritional management of the post-bariatric surgery patient: an Endocrine Society Clinical Practice Guideline. J Clin Endocrinol Metab 2010;95:4823-43. doi:10.1210/ jc.2009-2128.

23 Johnson IM, Maher IW, Samuel I, Heitshusen D, Doherty C, Downs RW. Effects of gastric bypass procedures on bone mineral density, calcium, parathyroid hormone, and vitamin D. J Gastrointest Surg 2005;9:1106-10, discussion 1110-1. doi:10.1016/i. gassur.2005.07.012.

24 Blais C, Sirois C, Rochette L, et al. Le Système Intégré de Surveillance des Maladies Chroniques du Québec (SISMACQ): une approche novatrice. Chronic Dis Inj Can 2014:34:247-56.

25 Pampalon R, Hamel D, Gamache P, Philibert MD, Raymond G, Simpson A. An area-based material and social deprivation index for public health in Québec and Canada. Can J Public Health 2012;103(Suppl 2):S17-22.

26 Quan H, Sundararajan V, Halfon P, et al. Coding algorithms for defining comorbidities in ICD-9-CM and ICD-10 administrative data. Med Care 2005:43:1130-9. doi:10.1097/01 mlr.0000182534.19832.83.

27 Klabunde CN, Potosky AL, Legler JM, Warren JL. Development of a comorbidity index using physician claims data. / Clin Epidemiol 2000:53:1258-67. doi:10.1016/S0895-4356(00)00256-0.

28 Golob AL, Laya MB. Osteoporosis: screening, prevention, and management. Med Clin North Am 2015;99:587-606. doi:10.1016/j. mcna.2015.01.010.

29 Soltani S, Hunter GR, Kazemi A, Shab-Bidar S. The effects of weight loss approaches on bone mineral density in adults: a systematic review and meta-analysis of randomized controlled trials. Osteoporos Int 2016; Epub ahead of print. doi:10.1007/s00198-016-3617-4.

30 Lebel S, Dion G, Marceau S, Biron S, Robert M, Biertho L. Clinical outcomes of duodenal switch with a 200-cm common channel: a matched, controlled trial. Surg Obes Relat Dis 2016;S15507289(16)00019-8; Epub ahead of print.

31 Robert M, Belanger P, Hould FS, Marceau S, Tchernof A, Biertho L. Should metabolic surgery be offered in morbidly obese patients with type I diabetes? Surg Obes Relat Dis 2015;11:798-805. doi:10.1016/j. soard.2014.12.016

32 Baillot A, Mampuya WM, Dionne IJ, Comeau E, Méziat-Burdin A, Langlois MF. Impacts of Supervised Exercise Training in Addition to Interdisciplinary Lifestyle Management in Subjects Awaiting Bariatric Surgery: a Randomized Controlled Study. Obes Surg 2016; Epub ahead of print. doi:10.1007/s11695-016-2153-9.

33 Johansson $\mathrm{H}$, Kanis JA, Odén A, et al. A meta-analysis of the association of fracture risk and body mass index in women. J Bone Miner Res 2014;29:223-33. doi:10.1002/jbmr.2017.

34 Sundh D, Rudäng R, Zoulakis M, Nilsson AG, Darelid A, Lorentzon M. A High Amount of Local Adipose Tissue Is Associated With High Cortical Porosity and Low Bone Material Strength in Older Women. J Bone Miner Res 2016;31:749-57. doi:10.1002/jbmr.2747.

35 Compston I. Obesity and bone. Curr Osteoporos Rep 2013:11:30-5. doi:10.1007/s11914-012-0127-y

36 Compston JE, Flahive J, Hosmer DW, et al. GLOW Investigators. Relationship of weight, height, and body mass index with fracture risk at different sites in postmenopausal women: the Global Longitudinal study of Osteoporosis in Women (GLOW). J Bone Miner Res 2014:29:487-93. doi:10.1002/jbmr.2051.

37 Armstrong ME, Cairns BJ, Banks E, Green I, Reeves GK, Beral V. Million Women Study Collaborators. Different effects of age, adiposity and physical activity on the risk of ankle, wrist and hip fractures in postmenopausal women. Bone 2012;50:1394-400. doi:10.1016/j. bone.2012.03.014

38 Prieto-Alhambra D, Premaor MO, Fina Avilés F, et al. The association between fracture and obesity is site-dependent: a population-based study in postmenopausal women. J Bone Miner Res 2012;27:294-300. doi:10.1002/jbmr.1466.

39 Hage MP, El-Hajj Fuleihan G. Bone and mineral metabolism in patients undergoing Roux-en-Y gastric bypass. Osteoporos Int 2014;25:42339. doi:10.1007/s00198-013-2480-9

40 Stein EM, Carrelli A, Young P, et al. Bariatric surgery results in cortical bone loss. J Clin Endocrinol Metab 2013;98:541-9. doi:10.1210/ jc.2012-2394. 
41 Berarducci A, Haines K, Murr MM. Incidence of bone loss, falls, and fractures after Roux-en-Y gastric bypass for morbid obesity. Appl Nurs Res 2009:22:35-41. doi:10.1016/j.apnr.2007.03.004.

42 Ikramuddin S, Billington CJ, Lee WJ, et al. Roux-en-Y gastric bypass for diabetes (the Diabetes Surgery Study): 2-year outcomes of a 5-year, randomised, controlled trial. Lancet Diabetes Endocrinol 2015;3:41322. doi:10.1016/S2213-8587(15)00089-3.

43 Chaston TB, Dixon JB, O'Brien PE. Changes in fat-free mass during significant weight loss: a systematic review. Int J Obes (Lond) 2007:31:743-50

44 Tarantino U, Piccirilli E, Fantini M, Baldi J, Gasbarra E, Bei R. Sarcopenia and fragility fractures: molecular and clinical evidence of the bone-muscle interaction. J Bone Joint Surg Am 2015;97:429-37. doi:10.2106/JBJS.N.00648.

45 Yu EW. Bone metabolism after bariatric surgery. J Bone Miner Res 2014:29:1507-18 doi:10.1002/jbmr.2226.

46 Muschitz C, Kocijan R, Haschka J, et al. The Impact of Vitamin D, Calcium, Protein Supplementation, and Physical Exercise on Bone Metabolism After Bariatric Surgery: The BABS Study. J Bone Miner Res 2016;31:672-82. doi:10.1002/jbmr.2707.

47 Karsenty G. Convergence between bone and energy homeostases: leptin regulation of bone mass. Cell Metab 2006;4:341-8. doi:10.1016/j.cmet.2006.10.008.

48 Abegg K, Gehring N, Wagner CA, et al. Roux-en-Y gastric bypass surgery reduces bone mineral density and induces metabolic acidosis in rats. Am J Physiol Regul Integr Comp Physiol 2013;305:R999-1009. doi:10.1152/ajpregu.00038.2013.

49 Canales BK, Schafer AL, Shoback DM, Carpenter TO. Gastric bypass in obese rats causes bone loss, vitamin D deficiency, metabolic acidosis, and elevated peptide YY. Surg Obes Relat Dis 2014;10:878-84. doi:10.1016/j.soard.2014.01.021.

50 Piché ME, Auclair A, Harvey J, Marceau S, Poirier P. How to choose and use bariatric surgery in 2015. Can J Cardiol 2015;31:153-66. doi:10.1016/j.cjca.2014.12.014

51 Mechanick JI, Youdim A, Jones DB, et al. American Association of Clinical Endocrinologists Obesity Society American Society for Metabolic \& Bariatric Surgery. Clinical practice guidelines for the perioperative nutritional, metabolic, and nonsurgical support of the bariatric surgery patient--2013 update: cosponsored by American Association of Clinical Endocrinologists, The Obesity Society, and American Society for Metabolic \& Bariatric Surgery. Obesity (Silver Spring) 2013;21(Suppl 1):S1-27. doi:10.1002/oby.20461.

52 Modi AC, Zeller MH, Xanthakos SA, Jenkins TM, Inge TH. Adherence to vitamin supplementation following adolescent bariatric surgery. Obesity (Silver Spring) 2013;21:E190-5. doi:10.1002/oby.20031.
53 Cooper PL, Brearley LK, Jamieson AC, Ball MJ. Nutritional consequences of modified vertical gastroplasty in obese subjects. Int J Obes Relat Metab Disord 1999:23:382-8. doi:10.1038/sj.ijo.0800830.

54 Dunstan MJ, Molena EJ, Ratnasingham K, et al. Variations in oral vitamin and mineral supplementation following bariatric gastric bypass surgery: a national survey. Obes Surg 2015;25:648-55. doi:10.1007/s11695-014-1425-5.

55 Marceau P, Biron S, Marceau S, et al. Long-Term Metabolic Outcomes 5 to 20 Years After Biliopancreatic Diversion. Obes Surg 2015;25:1584-93. doi:10.1007/s11695-015-1599-5.

56 Kim J, Eisenberg D, Azagury D, Rogers A, Campos GM. American Society for Metabolic and Bariatric Surgery position statement on long-term survival benefit after metabolic and bariatric surgery. Surg Obes Relat Dis 2016;12:453-9. doi:10.1016/j.soard.2015.11.021.

57 Sjöström L, Gummesson A, Sjöström CD, et al. Swedish Obese Subjects Study. Effects of bariatric surgery on cancer incidence in obese patients in Sweden (Swedish Obese Subjects Study): a prospective, controlled intervention trial. Lancet Oncol 2009;10:65362. doi:10.1016/S1470-2045(09)70159-7.

58 Sjöström L, Narbro K, Sjöström CD, et al. Swedish Obese Subjects Study. Effects of bariatric surgery on mortality in Swedish obese subjects. N Engl J Med 2007;357:741-52. doi:10.1056/NEJMoa 066254.

59 Courcoulas AP, Belle SH, Neiberg RH, et al. Three-Year Outcomes of Bariatric Surgery vs Lifestyle Intervention for Type 2 Diabetes Mellitus Treatment: A Randomized Clinical Trial. JAMA Surg 2015;150:931-40. doi:10.1001/jamasurg.2015.1534.

60 Cummings DE, Arterburn DE, Westbrook EO, et al. Gastric bypass surgery vs intensive lifestyle and medical intervention for type 2 diabetes: the CROSSROADS randomised controlled trial. Diabetologia 2016:59:945-53. doi:10.1007/s00125-016-3903-x

61 Sjöström CD, Lissner L, Wedel H, Sjöström L. Reduction in incidence of diabetes, hypertension and lipid disturbances after intentional weight loss induced by bariatric surgery: the SOS Intervention Study. Obes Res 1999;7:477-84. doi:10.1002/j.1550-8528.1999. tb00436.x.

62 Martin BJ, Chen G, Graham M, Quan H. Coding of obesity in administrative hospital discharge abstract data: accuracy and impact for future research studies. BMC Health Serv Res 2014;14:70. doi:10.1186/1472-6963-14-70.

(c) BMJ Publishing Group Ltd 2016

\section{Appendix 1}

